
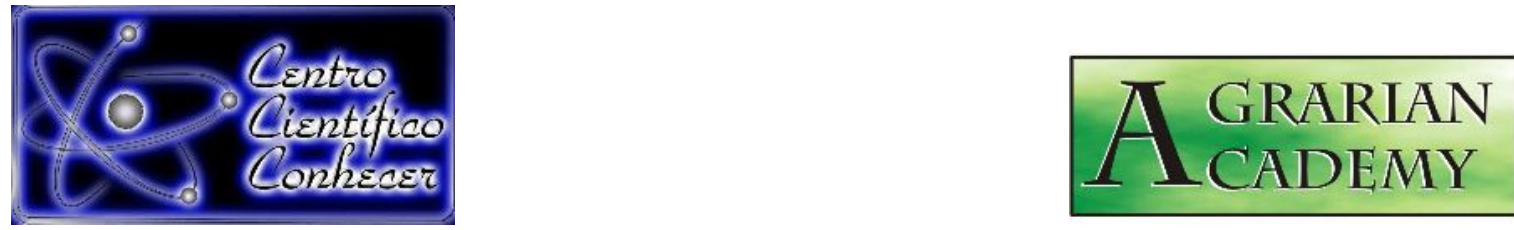

\title{
AVALIAÇÃO DE FLORESTAS PRIMÁRIAS E SECUNDÁRIAS EM APP DO RIO TELES PIRES POR MEIO DE SENSORES ORBITAIS
}

Lucas Santos Santana1, Oclizio Medeiros das Chagas Silva², Mozarte Santos Santana ${ }^{3}$, Gabriel Araújo e Silva Ferraz ${ }^{4}$, Lucas Amaral de Melo ${ }^{5}$

1. Mestrando em Engenharia Agrícola na UFLA, Departamento de Engenharia Agrícola, Lavras MG - Brasil, lucas.unemat@hotmail.com

2. Mestrando em Engenharia Florestal na UFLA

3. Doutorando em Agroquímica na UFLA

4. Professor DSc, Departamento de Engenharia Agrícola UFLA

5. Professor DSc, Departamento de Engenharia Florestal UFLA

Recebido em: 14/07/2018 - Aprovado em: 28/07/2018 - Publicado em: 31/07/2018

DOI: 10.18677/Agrarian_Academy_2018a7

\begin{abstract}
RESUMO
Em função da demanda mundial por alimentos o Brasil enfrenta um duro dilema, aliar expansão agrícola e preservação ambiental. Para isso pesquisas sobre mudanças na floresta e áreas de preservação permanente (APP), vem sendo implementadas de maneira sistemática e uma das ferramentas exploradas nas últimas décadas é o sensoriamento remoto. Estudar a dinâmica de áreas de APP em rios, pode auxiliar no entendimento das mudanças temporais contribuindo com as pesquisas hídricas e adequação em legislações. O objetivo deste trabalho foi identificar a dinâmica de florestas primárias e secundárias, nas matas ciliares do rio Teles Pires em região de atividade agrícola por meio de sensores remotos. Área de estudo contempla as margens do rio Teles Pires, na divisa dos municípios de Sinop e Sorriso (MT), em um perímetro de $86 \mathrm{~km}$. Para tal analise foram adquiridas um conjunto de imagens orbitais do sensor Landsat 05 e 08, nos anos de 2003, 2010 e 2017. Para o estudo de florestas primárias e secundárias foi realizado a uma composição RGB nas imagens e aplicado um índice de vegetação NDVI, em seguida foram identificados pontos de floresta secundária na cena de 2003, assim comparando a evolução da floresta com os anos de 2010 e 2017. Os resultados apontaram uma evolução significativa nas áreas de APP do Rio teles Pires, e observando que regiões agrícolas, produzem respeitando a legislação ambiental vigente. Concluindo que os dados de sensoriamento remoto são aptos para tal mensuração e pode contribuir para analises de mudanças na legislação e preservação dos recursos hídricos.
\end{abstract}

PALAVRAS-CHAVE: Matas ripárias; Recuperação florestal; Sensoriamento Remoto. 


\title{
EVALUATION OF PRIMARY AND SECONDARY FORESTS IN APP OF THE TELES PIRES RIVER BY ORBITAL SENSORS
}

\begin{abstract}
Due to the world demand for food, Brazil faces a difficult dilemma, allying agricultural expansion and environmental preservation. For this, research about forest changes and permanent preservation areas (PPA) has been systematically implemented and one of the tools explored in recent decades is remote sensing. PPA area's dynamics study in rivers can help in understanding the temporal changes contributing to water research and adequacy in legislation. The objective of this work was to identify the dynamics of primary and secondary forests in river Teles Pires riparian forests in agricultural activity region by remote sensing. Study area contemplates the Teles Pires riverbanks, in the border of the Sinop and Sorriso County (MT), in an $86 \mathrm{~km}$ perimeter. For this analysis, orbital images set of the Landsat 05 and 08 sensors were acquired in the years 2003, 2010 and 2017. For the primary and secondary forests study, an RGB composition was applied to the images and an NDVI vegetation index was applied, then secondary forest points were identified in the 2003 scene, thus comparing forest evolution in the next years 2010 and 2017 . The results indicated out a significant evolution in the river Teles Pires PPA areas and show that agricultural regions produce in compliance with the current environmental legislation. The remote sensing data are suitable for such measurement and can contribute to analyze of changes in legislation and water conservation.
\end{abstract}

KEYWORDS: Riparian vegetation; Forest recovery; Remote Sensing.

\section{INTRODUÇÃO}

Sob boas condições para produção agrícola em diversas culturas, o Brasil se apresenta no cenário mundial como um celeiro agrícola de alto potencial, tanto em produção como expansão territorial, a produção de grãos que inicialmente ocupava o cerrado brasileiro nos últimos anos avança sobre a Amazônia. Segundo Ferreira et al. (2015) o processo do desmatamento na Amazônia Legal associa-se a fatores de mercado, tais como variações nos preços das commodities agrícolas, bem como às políticas governamentais. Com cerca de 100 milhões de hectares aptos à expansão, o plantio de grãos cresce nos países do Mercosul como Brasil, Argentina, Paraguai e Uruguai, assim como a presença de grandes empresas multinacionais nos segmentos de comercialização e industrialização, que se estende em áreas de produção de sementes e financiamentos da produção de grãos (DOMINGUES et al., 2014).

O grande desafio é aliar produção de alimentos com a preservação deste bioma. Lui e Molina (2009) afirmam que sob o contexto de intensificação e mudanças da cobertura do solo ao qual a Amazônia está submetida, pesquisas buscam compreender as transformações da paisagem no decorrer dos anos. Com a evolução nas tecnologias de produção, aberturas de novas áreas a obtenção de dados para o monitoramento da floresta amazônica também evoluiu. Atualmente ferramentas de sensoriamento remoto podem observar grandes porções de mata e campos de produção, acompanhando as mudanças na superfície terrestre. Para Shimabukuro et al. (2015), nas últimas décadas o sensoriamento remoto vem sendo explorado para o rápido monitoramento e avaliação de importantes variáveis ambientais. Bambolim e Donde (2017) complementam que técnicas de 
sensoriamento remoto permitem observar a evolução de uma região por meio de análises espaciais e temporais.

No monitoramento de superfícies, o sensor Landsat é bastante explorado pela comunidade cientifica e pelo governo, pelo acervo de imagens e boas resoluções espaciais e espectrais para monitoramento de mudanças na superfície. Segundo Roy et al. (2014), a utilização de dados Landsat envolve tanto a exploração científica, como a gestão e monitoramento de recursos para a economia e qualidade ambiental. Algumas técnicas de combinações de bandas espectrais se destacam nas cenas de origem orbital, como o uso de índices de vegetação. Para Zheng et al. (2015) o NDVI (Índice de Vegetação por Diferença Normalizada) oferece informações precisas específicas para várias culturas e é necessário em avaliações detalhadas de uso da água e para outras avaliações agroambientais. As combinações de técnicas de classificação aliadas a ferramentas de sensoriamento remoto ajudam compreender a dinâmica da floresta ao longo de anos.

Com a instalação de áreas de agricultura nota se fortes pressões sobre a floresta e sua malha hidrográfica. As margens de rios que segundo a legislação do código florestal Lei $\mathrm{N}^{\circ} 12.651 / 2012$ pertencem a área de preservação permanente e cumprem papel na manutenção das águas e a presença de florestas primárias. As áreas do entorno de rio e nascentes apresentam suma importância no que diz respeito à vida útil dos rios, uma vez que sem a proteção adequada em torno notase um processo de rápida degradação (DONADIO et al., 2005).

Um dos primeiros sintomas apresentados em uma floresta no inicio de degradação é o surgimento de florestas secundárias, pois este aparecimento indica alguma interferencia natural ou antrópica, diminuindo a densidade florestal e a presença de espécies lenhosas. Para condições de matas ciliares as florestas nativas podem oferecer maior resistência aos processos de degradação como enxurradas e assoreamento dos rios (ZELARAYÁN et al., 2015).

No entanto o monitoramento dessas mudanças torna-se necessário para tomadas de decisão em relação a políticas de legislação ambiental e expansão agrícola. Diante do tema abordado este trabalho teve como objetivo identificar a dinâmica de florestas primárias e secundárias, nas matas ciliares do rio Teles Pires em região de atividade agrícola por meio de sensores remotos.

\section{MATERIAL E MÉTODOS}

A área de estudo contempla as margens do rio Teles Pires na divisa dos municípios de Sinop e Sorriso - MT entre as coordenadas latitude $12^{\circ} 9^{\prime} 10.85^{\prime \prime S}$ e

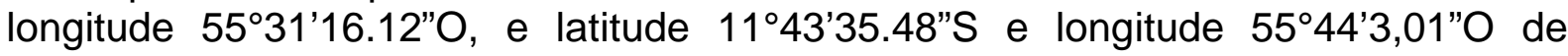
Greenwich, ocupando um perímetro de 86,8 km (Figura 01). 


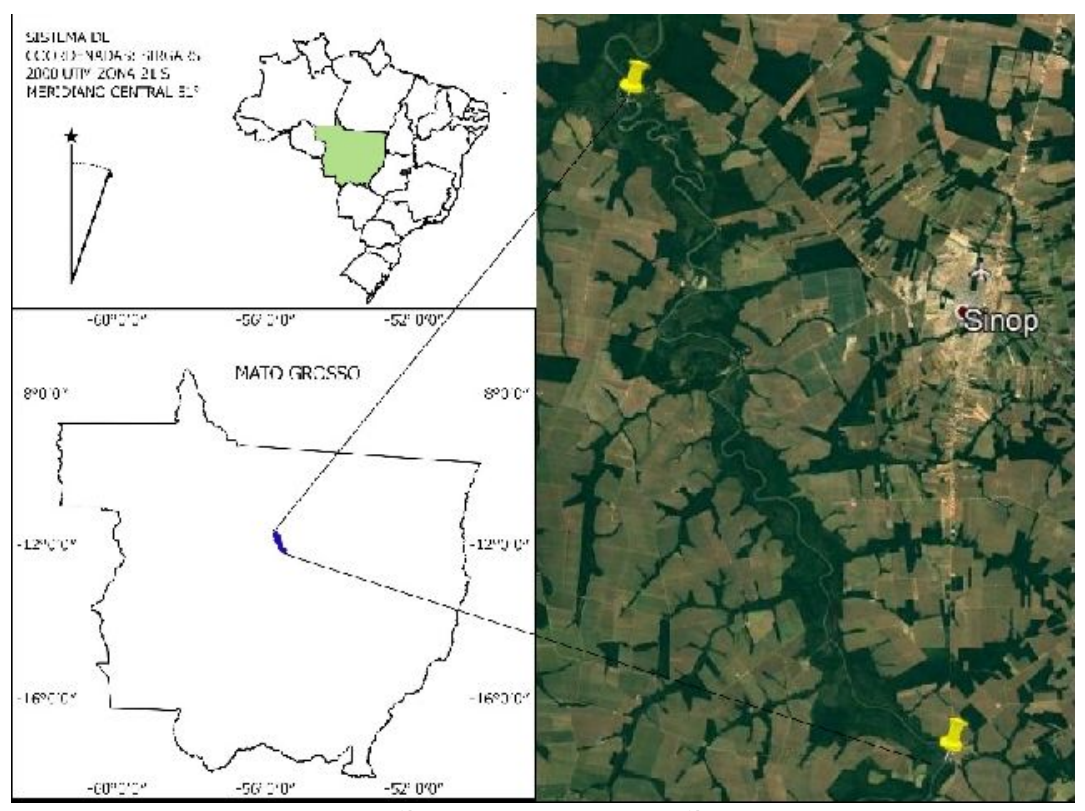

FIGURA 01. localização da extensão do rio Teles Pires pesquisada no estado do Mato Grosso. Fonte: Google Earth e IBGE.

Segundo Köppen com adaptações de Alvares et al. (2013) a região é caracterizada como (AW), sendo clima tropical com estação seca de inverno com médias anuais de temperatura entre 24 a $26 C^{\circ}$, pluviosidades entre 1900 a 2200 $\mathrm{mm}$ anuais com altas precipitações no verão e altitude entre 300 a 400 metros. No estado do Mato Grosso, o clima Aw vem do Sul com uma precipitação anual de $1.400 \mathrm{~mm}$ (região do Pantanal) e atravessa a parte central do estado, Planalto Parecis, onde a precipitação anual varia de 1.800 a $2.300 \mathrm{~mm}$ sendo, portanto, considerada a Aw mais úmida do País.

Esses dados mostram que a região apresenta condições ótimas para instalações de agricultura. A região localizada no médio-norte mato-grossense é um dos polos econômicos da macrorregião, destacando-se recentemente pela instalação de um grande número de indústrias no município e pela intensa expansão das fronteiras agrícolas (ROCHA et al., 2015).

Para processamento e análise dos dados foram adquiridos conjuntos de imagens orbitais, disponibilizadas no acervo digital do serviço geológico do EUA (USGS - Earth Explorer) oriundos dos sensores Landsat 05 e 08, entre junho e agosto. São escolhidos esses meses, pois são as épocas com menor presença de nuvens, que podem atrapalhar a geração de índice e classificação. Resultados de Pinagé e Matricard (2015) explicam que imagens adquiridas na estação chuvosa podem ter as análises comprometidas, pois a vegetação está no vigor máximo e a saturação, com vegetação densa, o NDVI pode ter o desempenho diminuído. Nesse trabalho a acurácia da classe floresta elevou fortemente os valores da acurácia global para todas as classificações.

Para tal observação foram escolhidas nos anos 2003, 2010 e 2017, assim descritas na (Quadro 1). As duas primeiras épocas são imagens do Landsat 05, pois este entrou em operação em janeiro de 1984 e encerrou as operações em outubro de 2013 (INPE, 2018), impossibilitando a aquisição da última época. Para extração de informações a respeito do ano de 2017, foram obtidas cenas do Landsat 08, que entrou em funcionamento em fevereiro de 2013 (INPE, 2018). 
QUADRO 1. Características dos sensores Landsat e época de aquisição dos dados.

\begin{tabular}{|c|c|c|}
\hline Sensores & Data & Órbita / Ponto \\
\hline LANDSAT 05 & $13 / 08 / 2003$ & $227 / 068$ \\
\hline LANDSAT 05 & $31 / 07 / 2010$ & $227 / 068$ \\
\hline LANDSAT 08 & $03 / 08 / 2017$ & $227 / 068$ \\
\hline
\end{tabular}

Em seguida, foi feito o tratamento dos dados no software Qgis 2.18, configurando parâmetros de datum e sistema de coordenadas. Na sequência realizou se o corte da imagem, deixando só a região de estudo para facilitar o trabalho no processamento e diminuir o espaço o ocupado em hardware, visto que a imagem Landsat tem $170 \times 170 \mathrm{~km}$. Definido isso realizou-se uma composição RGB cor natural por meio da ferramenta (band set), no próprio software de SIG.

Para identificação das áreas de florestas secundárias e primárias, identificouse um trecho do Rio Teles Pires na divisa dos municípios de Sorriso e Sinop - MT, na região central do Estado, com comprimento de $86 \mathrm{~km}$, realizando um buffer numa faixa de 100 metros da margem do rio, largura especificada como APP (Quadro 2).

QUADRO 2. Normas para APPs segundo o código florestal Lei № 12.651/2012.

\begin{tabular}{|c|c|}
\hline Largura dos cursos de água $(\mathrm{m})$ & APP $(\mathrm{m})$ \\
\hline$>10$ & 30 \\
\hline 10 a 50 & 50 \\
\hline 50 a 200 & 100 \\
\hline 200 a 600 & 200 \\
$<600$ & 500 \\
\hline
\end{tabular}

$\mathrm{Na}$ identificação das feições da floresta (primária e secundária) foi aplicado o Índice de Vegetação da Diferença Normalizada (NDVI), que segundo Robinson et al. (2017) é dado por:

$$
N D V I=\frac{\rho \mathrm{NIR}-\rho \mathrm{RED}}{\rho \mathrm{NIR}+\rho \mathrm{RED}}
$$

Em que: $\rho$ NIR representa a refletância na faixa espectral do infravermelho próximo e $\rho R E D$ a refletância na faixa espectral do vermelho. Esse índice apresenta valores que variam entre -1 e 1 . Devido diferenças entre distribuição da cobertura vegetal e diferentes regiões, esses valores entre cobertura com ausência e presença de vegetação foi definido com base em uma distribuição histograma dos valores de NDVI após uma extensa análise estatística de um número inteiro de pixels das regiões correspondentes (MA et al., 2017).

Após aplicação do índice NDVI, foram identificados pontos de floresta secundária na imagem de 2003, onde foram identificados 34 pontos de possíveis interferências naturais ou antrópicas. Analisando as mudanças nos pontos nas cenas de 2010 e 2017, por meio da ferramenta identificador de feições do QGis 2.18, ou seja, cada pixel foi classificado de acordo com os valores de NDVI, abaixo de 0,5 para floresta primária e acima de 0,5 para floresta secundaria. 


\section{RESULTADOS E DISCUSSÃO}

Os primeiros resultados obtidos podem ser observados na (Figura 02), ilustrando o posicionamento e identificação de 34 pontos de floresta secundária. Segundo Powell et al. (2015) caracteriza se vegetação primária como a região de floresta natural ou com total regeneração, após ter sofrido impacto natural ou humano, e secundária é a presença de plantas de crescimento rápido e em processo de recomposição, e salientam que a medida que avança a diminuição da floresta tropical as manchas de floresta primária continuam a ser fragmentadas por estradas, agrícolas, florestas secundárias.

Os pontos identificados foram relacionados a partir de trabalhos como de Ma et al. (2017) que descrevem a relação entre presença de vegetação com bandas espectrais confirmando que a vegetação tem forte refletividade na banda do infravermelho próximo (NIR) e fraca refletividade na banda vermelha $(R)$, que são representadas pelas bandas 04 e 03 nas imagens Landsat 05 e bandas 04 e 05 para Landsat 08. Para boas interpretações dos resultados, as cenas são da época de inverno (aw -estação seca), como pode ser vista na (Figura 02), expondo um índice NDVI com alta nitidez e facilitando o reconhecimento dos pontos. Ferreira (2016) atenta para esse caso relatando que sombras e presença de nuvens pode gerar falsa interpretação entre florestas primárias e secundárias dificultando o trabalho do analista.

Os resultados de NDVI expostos na (Figura 02) indicam que variaram entre 0,0967 e 0,645 , e foi considerado floresta secundária valores abaixo de 0,5 sem considerar a característica da interferência pode ser ação antrópica ou natural. Segundo França et al. (2017) as variações contínuas dos valores de NDVI estimados por meio de combinações nas bandas espectrais são eficientes para identificação de feições da superfície terrestre e na distinção de categorias dos diversos tipos de uso e cobertura da terra, e apresenta eficiência para medir o vigor vegetativo.

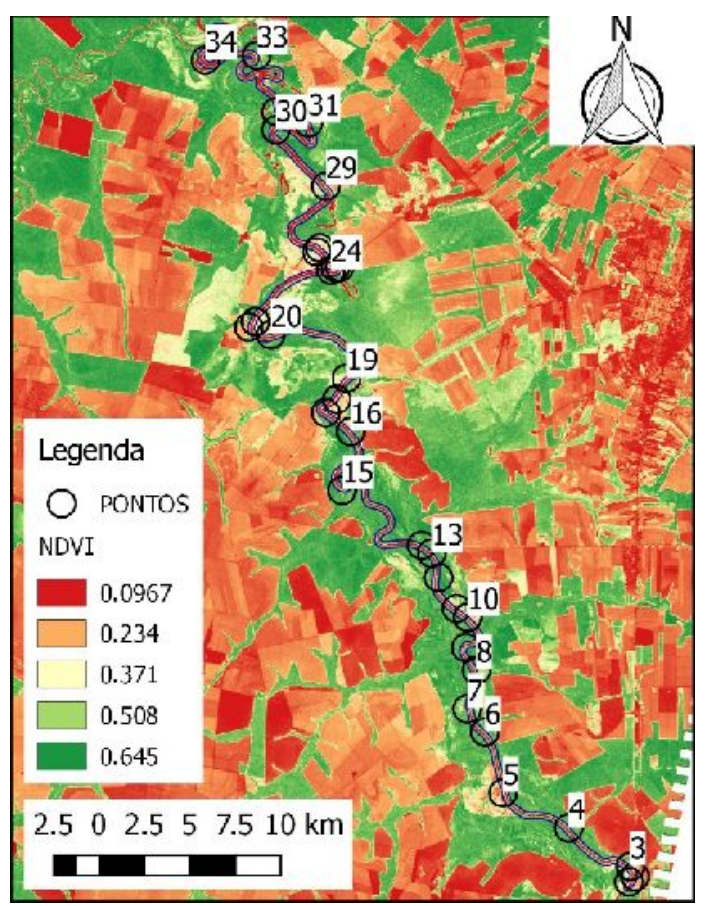

FIGURA 02. Pontos de floresta secundária identificados em cena LANDSAT 05- 2003 com composição NDVI. Fonte: Elaborado pelos autores. 
$\mathrm{Na}$ (Figura 03) observa-se a identificação dos pontos e evolução da recomposição florestal ao longo das épocas analisadas, nota se o incremento de vegetação natural no ponto 31, com valor inicial de 0,0234 em 2003 e indo para $0,508 \mathrm{em} 2017$. Esses dados corroboram com as pesquisas realizadas em florestas secundárias por Silva et al. (2015), publicaram resultados identificando alterações na dinâmica de uso das florestas secundárias em regiões Amazônicas, com destaque para a mudanças ocorridas no período de pousio. Deixando evidente que as alterações feitas em APP 2003, foram deixadas em pousio, pois observa-se a rápida regeneração. Diante dos resultados foi possível observar que em toda área estudada nenhum ponto está fora da legislação, pois esta não especifica qual tipo de floresta deve existir em APP. Isso pode ser visto na delimitação em azul apresentado na (Figura 02).
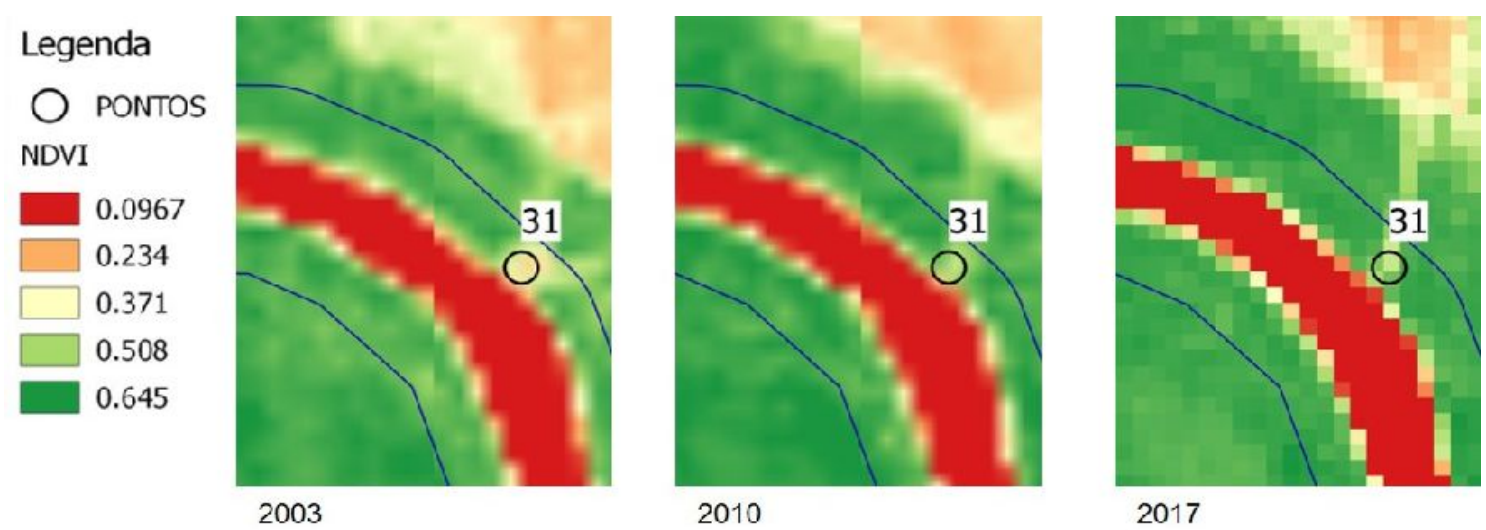

FIGURA 03. Mudança do ponto (31) florestas secundárias em primárias cenas LANDSAT 05 e 08 de 2003 - 2017, composição NDVI. Fonte: Elaborado pelos autores.

Contrariando resultados encontrados e discutidos por outros autores como o trabalho de Almeida e Vieira (2014), afirmando que a expansão agropecuária principalmente para a produção de biodiesel no município de Moju-PA, compromete diretamente a manutenção das matas ciliares da região. Os dados da (Figura 04) mostram uma recuperação dos pontos encontrados, em relação a 2003 foram notados em 2017, 23 pontos de florestas primárias, fazendo entender que em áreas agrícolas a interferência nas regiões de APP são poucas, isso pode estar ligado a com a adequação ambiental do CAR ambiental rural.

Em 2012 o governo federal iniciou a realização do mapeamento de todas as propriedades rurais do país para conhecer a situação ambiental e propor novas legislações. Os pontos que não apresentaram regeneração natural podem ser ponto de coleta de água para pulverização e irrigação ou travessias realizadas por pequenas balsas. 


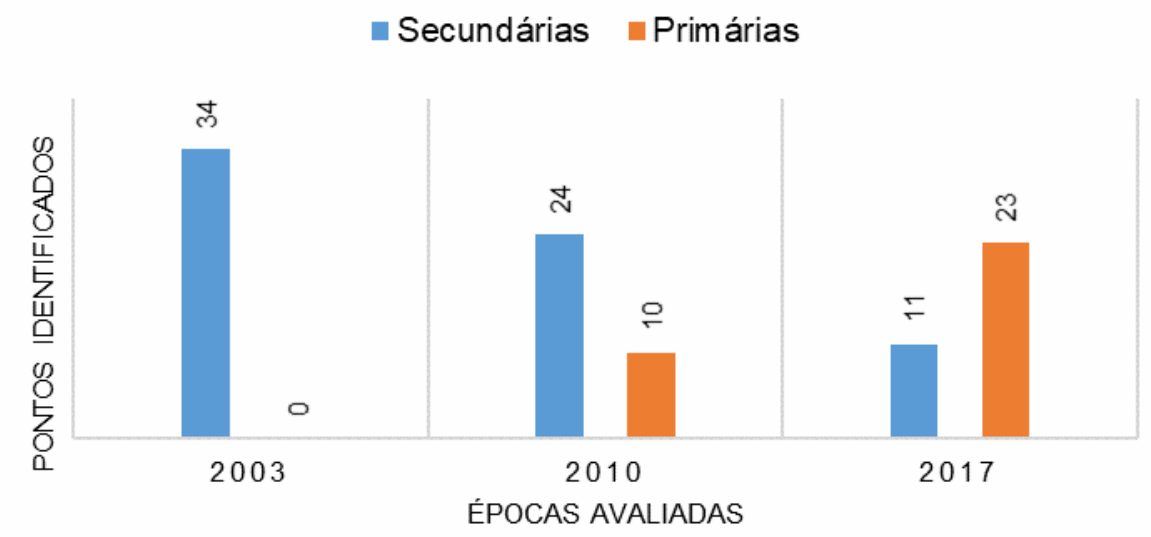

FIGURA 04. Transição dos pontos de floresta secundária para primária. Fonte: Elaborado pelos autores.

Alguns estudos relacionam a pressão agrícola sobre áreas de APPs e rios, essa premissa pode ser revisada e dividida entre pecuária e agricultura, pois o sistema de pecuária geralmente utiliza os rios como bebedouros dos animais, como enfatiza Nunes et al. (2015) que estudaram a dinâmica de microbacias e concluíram que a presença de animais exerce forte pressão de sobre matas ciliares.

Esse fato também foi observado em estudos de Miranda (2016) encontrando ocorrências de florestas secundárias em seu mapeamento e direcionando essa responsabilidade a pecuária, afirmando que, o desmatamento da cobertura vegetal ao longo das margens dos cursos de água pode afetar as águas superficiais, em decorrência da quantidade de sedimentos carreados para dentro do leito.

\section{CONCLUSÃO}

Ao processar os dados oriundos de sensores remotos e relacionar com outros trabalhos, foi possível identificar as variações entre floresta primária e secundária.

O método NDVI pode ser aplicado para este tipo de monitoramento e ficando evidente as boas resoluções dos sensores Landsat 05 e 08.

A utilização de imagens de satélite é uma ferramenta que pode ser fundamental em estudos dirigidos à dinâmica ambiental, contemplando zonas de rios.

\section{REFERÊNCIAS}

ALMEIDA, A. S.; VIEIRA, I. C. G. Conflitos no uso da terra em Áreas de Preservação Permanente em um polo de produção de biodiesel no Estado do Pará. Ambiente e Agua, $\quad$ v. $\quad 9, \quad$ n. $3, \quad 2014 . \quad$ Disponível em: http://www.redalyc.org/pdf/928/92831698010.pdf, ISSN 1980-993X doi:10.4136/1980-993X.

ALVARES, C.A.; STAPE, J.L.; SENTELHAS, P.C.; DE MORAES, G.; LEONARDO, J.; SPAROVEK, G. Köppen's climate classification map for Brazil. Meteorologische Zeitschrift, v. 22, n. 6, p. 711-728, 2013. Disponível em: https://www.ingentaconnect.com/content/schweiz/mz/2013/00000022/00000006/art0 0008. https://doi.org/10.1127/0941-2948/2013/0507.

BAMBOLIM, A.; DONDE, A. R. Análise temporal da microbacia Mariana no município 
de Alta Floresta, Mato Grosso. Revista de Agricultura Neotropical, v. 4, n. 3, p. 2017.

http://periodicosonline.uems.br/index.php/agrineo/article/view/1613.

DOMINGUES, M. S.; BERMANN, C.; MANFREDINI, S. A produção de soja no Brasil e sua relação com o desmatamento na Amazônia. RPGeo, v. 1, n. 2014, p. 32-47, 2014. Disponível em: http://www.periodicos.unir.br/index.php/RPGeo/article/view/2308. ISSN 2446-6646.

DONADIO, N. M. M.; GALBIATTI, J. A.; PAULA, R. C. DE. Qualidade da água de nascentes com diferentes usos do solo na bacia hidrográfica do córrego rico, São Paulo, Brasil. Engenharia Agrícola, v. 25, n. 1, p. 115-125, 2005. Disponivel em: http://www.scielo.br/pdf/\%0D/eagri/v25n1/24877.pdf.

FERREIRA, J. Análise comparativa dos métodos de classificação da vegetação NDVI e análise por componentes principais em uma imagem Rapideye. Cadernos do Leste, Vol.16, $n^{\circ} 16, \quad 2016 . \quad 19 p$. Disponível em: http://www.igc.ufmg.br/portaldeperiodicos/index.php/leste/article/view/1125.

FERREIRA, M. D. P.; COELHO, A.B. Desmatamento Recente nos Estados da Amazônia Legal: uma análise da contribuição dos preços agrícolas e das políticas governamentais. Revista de Economia e Sociologia Rural, v. 53, n. 1, p. 91-108, 2015. Disponível em: http://www.scielo.br/scielo.php?pid=S010320032015000100091\&script=sci_arttext. DOI://dx.doi.org/10.1590/1234-567818069479005301005.

FRANÇA, L. C.; DOS SANTOS LISBOA, G.; DA SILVA, J.B.L.; CERQUEIRA, C.L.; STEPKA, T.F. Uso e cobertura da terra para o município de Clevelândia, Paraná, Brasil. Agrarian, v.10, $\mathrm{n}$ 38, p. 371-384, 2017. Disponível em: http://ojs.ufgd.edu.br/index.php/agrarian/article/view/6728.

DOI: //doi.org/10.30612/agrarian.v10i38.6728. http://hdl.handle.net/10174/18761. ISSN: 0124-177X.

INSTITUTO NACIONAL DE PESQUISAS ESPACIAIS (INPE). Disponível em: http://www.dgi.inpe.br/documentacao/satelites/landsat. Acesso em: 10 junho 2018.

LUI, G. H.; MOLINA, S. M. G. Ocupação humana e transformaçao das paisagens na Amazônia brasileira. Amazonica, v. 1, p. 200-228, 2009. Disponível em: https://periodicos.ufpa.br/index.php/amazonica/article/view/156. ://dx.doi.org/10.18542/amazonica.v111.156.

MA, X.; TONG, X.; LIU, S.; LUO, X.; XIE, H. et al. Optimized sample selection in SVM classification by combining with DMSP-OLS, landsat NDVI and GlobeLand30 products for extracting urban built-up areas. Remote Sensing, v. 9, n. 3, p. 236, 2017. Disponível em: http://www.mdpi.com/2072-4292/9/3/236/html. DOI:10.3390/rs9030236.

MIRANDA, C.; ROSA, L.; GOLÇALVES, N.; OLIVEIRA, F.; BONITO, J. Impactos ambientales en la microcuenca del río Parafuso, Amazonas oriental, Brasil. Gestión y Ambiente. v. 19, n. 1, p. 123-140, 2016. Disponível em: 
http://www.revistas.unal.edu.co/index.php/gestion/article/view/52989.

NOVO CÓDIGO FLORESTAL Lei no 12.651, de 25 de maio de 2012. Disponível em: http://saema.com.br/files/Novo\%20Codigo\%20Florestal.pdf.

NUNES, E.J.; DA SILVA, E.P.; DE SOUZA, E.; DA ROCHA FILHO, J.A.; DA SILVA, D.S.N. Geotecnologias no diagnóstico de conflitos de uso do solo de uma microbacia do município de Alta Floresta - MT. Ciencia Florestal, v. 25, n. 3, p. 689-697, 2015. Disponível em: http://www.redalyc.org/pdf/534/53441497014.pdf. ISSN: 0103-9954.

PINAGÉ, E. R.; MATRICARDI, E. A. T. Detecção da Infraestrutura para Exploração Florestal em Rondônia Utilizando Dados de Sensoriamento Remoto. Floresta e Ambiente, $\quad \mathrm{v}$ 22, $\mathrm{n} \quad 3, \quad$ p. 377-390, 2015. Disponível em: http://www.scielo.br/scielo.php?script=sci_arttext\&pid=S2179-

$80872015000300377 \&$ lng=pt\&tlng=pt. DOI://dx.doi.org/10.1590/2179-8087.064013.

POWELL, L.L.; ZURITA, G.; WOLFE, J.D.; JOHNSON, E.I.; STOUFFER, P.C. Changes in habitat use at rainforest edges through succession: A case study of understory birds in the Brazilian Amazon. Biotropica, v. 47, n. 6, p. 723-732, 2015. Disponível em: https://onlinelibrary.wiley.com/doi/abs/10.1111/btp.12253. DOI: //doi.org/10.1111/btp.12253.

ROBINSON, N.P.; ALLRED, B.W.; JONES, M.O.; MORENO, A.; KIMBALL, J.S. et al. A dynamic landsat derived normalized difference vegetation index (NDVI) product for the conterminous United States. Remote Sensing, v. 9, n. 8, p. 1-14, 2017. Disponível em: http://www.mdpi.com/2072-4292/9/8/863. DOI: //doi.org/10.3390/rs9080863.

ROCHA, A. F.; DE PAULA, D.C.J.; SANCHES, N.; DA SILVA, P.C.B.; DE MIRANDA, S.A. et al. variações microclimáticas de áreas urbanas em biomas no estado de mato grosso: Cuiabá e Sinop. Revista Gestão Sustentável Ambiental, v. especial, p. 246-257, 2015. Disponível em: http://www.portaldeperiodicos.unisul.br/index.php/gestao_ambiental/article/view/3355 . DOI: //dx.doi.org/10.19177/rgsa.v4e02015246-257.

ROY, D. P.; WULDER, M.A.; LOVELAND, T.R.; WOODCOCK, C.E.; ALLEN, R.G. et al. Landsat-8: Science and product vision for terrestrial global change research. Remote Sensing of Environment, v. 145, p. 154-172, 2014. Disponível em: https://www.sciencedirect.com/science/article/pii/S003442571400042X. DOI: //doi.org/10.1016/j.rse.2014.02.001.

USGS - Serviço Geológico do Estados Unidos. Disponível: https://earthexplorer.usgs.gov/. acesso em: 10 junho 2018.

SHIMABUKURO, Y. E.; MAEDA, E. E.; FORMAGGIO, A. R. Sensoriamento Remoto e Sistemas de Informações Geográficas aplicados ao estudo dos recursos agronômicos e florestais. Ceres, v. 56, n. 4, p. 399-409, 2015. Disponível em: http://www.ceres.ufv.br/ojs/index.php/ceres/article/view/3443. ISSN 0034-737X. 
SILVA, M. M. DA; OLIVEIRA, F. DE A.; SANTANA, A. C. Mudanças na dinâmica de uso das florestas secundárias em Altamira, Estado do Pará, Brasil. Revista de Ciências Agrárias, v. 58, n. 2, p. 176-183, 2015. Disponível em: http://periodicos.ufra.edu.br/index.php/ajaes/article/view/1739. ISSN 2177-8760.

ZELARAYÁN, M.L.; CELENTANO, D.; OLIVEIRA, E.C.; TRIANA, S.P.; SODRÉ, D.N. et al. Impacto da degradação sobre o estoque total de carbono de florestas ripárias na Amazônia Oriental, Brasil. Acta Amazonica, v. 45, n. 3, p.271-282, 2015. Disponível em: http://www.scielo.br/scielo.php?script=sci_arttext\&pid=S004459672015000300271\&lng=pt\&tlng=pt. DOI: http://dx.doi.org/10.1590/18094392201500432.

ZHENG, B.; Myint, S.W.; Thenkabail, P.S.; Aggarwal, R.M. A support vector machine to identify irrigated crop types using time-series Landsat NDVI data. International Journal of Applied Earth Observation and Geoinformation, v. 34, n. 1, p. 103112, 2015.2 Disponível em: https://www.sciencedirect.com/science/article/pii/S0303243414001615. DOI: //doi.org/10.1016/j.jag.2014.07.002. 